\title{
NILAI GOTONG ROYONG DALAM TATAK TINTOA SERSER PADA MASYARAKAT PAKPAK BHARAT
}

\author{
TRIJAYANTI SIREGAR \\ Prodi Pendidikan Tari
}

\begin{abstract}
Peoples Pakpak called the term dance with the wordTatak. Tatak Tintoa Serser (mangirik page) describes the work to harvest rice from beginning to end. This study aims to explore the value of mutual cooperation contained in Tatak Tintoa Serser views from the variety of motion.

The cornerstone of the theory used in this study is an understanding of the value and the theory of solidarity.

Time used in research to address Tatak Tintoa Serser carried out since January 2016 to March 2016. The study was conducted in the village of Salak, District Salak, Pakpak Bharat. The population once the sample in this study is a resource and dancers who controlled the culture and dance. Data collection techniques including observation, interviews, literature study and documentation, which is then analyzed by qualitative descriptive method.

The results obtained are moral values such as solidarity and mutual aid values are reflected through movements that are arranged in Tatak Tintoa Serser namely motion Mangirik Page, motion Manarsari, motion Erserakan Page, motion Mangumpulkan Page and motion carry on the hand Page.
\end{abstract}

Keywords: Tatak Tintoa Serser, the value of mutual cooperation 


\section{PENDAHULUAN}

Pulau Sumatera merupakan salah satu pulau terbesar di Indonesia dan memiliki penduduk dengan beraneka ragam suku. Suku Batak merupakan salah satu suku yang dapat ditemui di Sumatera bagian Utara yang ber-ibukota Medan. Suku Batak ini terbagi lagi menjadi beberapa bagian dengan adat istiadatnya masing-masing, yaitu; Suku Batak Toba, Suku Mandailing/Angkola, Suku Karo, Suku Pakpak, dan Suku Simalungun. Setiap suku yang ada di Sumatera Utara memiliki khas Kebudayaannya masing-masing sebagai ciri suku tersebut. Segala sesuatu yang terdapat dalam masyarakat ditentukan oleh kebudayaan yang dimiliki masyarakat itu. Suku Pakpak memiliki berbagai jenis kesenian antara lain : Seni Musik, Seni Tari dan Seni Teater.Tarian tradisional Pakpak sangat erat kaitannya dengan kehidupan sehari-hari.

Aktivitas masyarakat Pakpak adalah menanam Padi di Huma/di Ladang. Mata pencaharian masyarakat Pakpak masih mengandalkan sistem pertanian yang tertuju kepada macam-macam penghasilan yang diantaranya adalah bertani padi, jagung, coklat, cabai dan lain-lain. Masyarakat Pakpak menyebutkan istilah tari dengan istilah Tatak. Sementara menari disebut Tumatak. Tatak Tintoa Serser menggambarkan tentang bagaimana masyarakat Pakpak dalam bercocok tanam, mulai dari memanen padi, mengirik, membersihkan dan membawa pulang hasil panen padi tersebut. Tatak Tintoa Serser (mangirik page) tarian ini menggambarkan pekerjaan panen padi, yaitu memisahkan bulir-bulir padi dari tangkainya. Hal ini dilakukan dengan cara menginjakinjak padi yang masih melekat pada tungkainya dan hal ini tidak dilakukan sendiri saja tetapi secara bersama-sama, supaya pekerjaan memanen lebih cepat selesainya. Aktivitas ini bagi masyarakat Pakpak dikenal dengan istilah mangirik atau menerser. Tatak Tintoa serser diciptakan oleh Djauli Padang Batang Hari pada Tahun 70an. Tarian ini diciptakan untuk menggambarkan kebersamaan orang Pakpak dalam bertani. Tatak Tintoa Serser diamati dari gerak tangan, kaki dan kepala yang mempunyai ciri khasnya sendiri. Dalam setiap gerakannya mengandung nilai keindahan, nilai solidaritas dan nilai gotong royong.

Pada umumnya masyarakat desa adalah masyarakat yang hotorigen (kompak) yang di ikat oleh satu sistem kekeluargaan, budaya yang sama, adat yang sama. Salah satu yang paling bertahan bagi masyarakat desa adalah sistem gotong royong. Gotong Royong menggambarkan perilaku-perilaku masyarakat pertanian desa yang bekerja untuk yang lainnya tanpa 
menerima upah, dan lebih luas sebagai suatu tradisi yang mengakar bagi masyarakat. Tradisi gotong royong bagi masyarakat desa masih bertahan dan gotong royong sebagai sebuah kekuatan sosial atau solidaritas yang harus tetap ada dan di pertahankan. Tak terkecuali bahwa pada masa-masa kritis seperti musim panen, musim kemarau, musim semi, masyarakat desa tetap menjaga solidaritas dan kebersamaan yang di bangun jarang sekali luntur, biarpun ada musim gagal panen atau musim kemarau yang membuat satu dengan lainnnya saling membantu dan saling gotong royong

Lingkungan disekitar kita dapat mempengaruhi adanya rasa solidaritas seperti bagaimana cara kita bergaul dan berteman di dalam lingkungan. Contoh solidaritas dapat dilihat di dalam Tatak Tintoa Serser, ketika masyarakat bersama-sama mengerjakan pekerjaan panen padi karena adanya rasa kebersamaan dari setiap orang yang ada pada lingkungan tersebut dan terjalinnya rasa kekompakan dan kepedulian terhadap sesama. Karena adanya rasa solidaritas ini maka timbul lah rasa untuk saling membantu dan melakukan aktivitas memanen bersama-sama, tindakan ini disebut Gotong-royong.

Unsur gotong royong tersebut kadang terdiri dari aspek-aspek yang terdiri karena rasa kekeluargaan, persamaan, nasib dan norma yang berlaku. Gotong royong bagi masyarakat desa dapat diartikan sebagai aktivitas sosial. Aktivitas sosila disini adalah, intraski sosial, prilaku sosial, dan solidaritas sosial yang di bangun bersama-sama, namun dalam hal yang paling penting dalam memaknainya solidaritas atau gotong royong antar sesama masyarakat desa adalah menjadikannya sebagai filosofi dalam hidup yang menjadikan kehidupan bersama sebagai aspek yang paling penting. Gotong royong adalah nilai yang menjadi bagian dari budaya Indonesia, khusunya masyarakat desa bukan hanya menjadi filosofi beberapa kelompok tertentu.

Nilai gotong royong bisa menjadi modal sosial dalam kehidupan bertetangga antar masyarakat karena dalam kehidupan sehari-hari manusia tidak lepas dari hubungan antara satu dengan yang lainnya. Ia akan selalu perlu untuk mencari individu ataupun kelompok lain dalam berinteraksi ataupun bertukar pikiran, dengan gotong royong masyarakat memiliki interaksi yang kuat dalam proses bersawah, kebersamaan dan kepedulian menjadikan mereka tolong-menolong.

\section{Landasan Teori}

Untuk mengupas dan membahas nilai gotong royong dalam Tatak Tintoa Serserpada 
masyarakat Pakpak Bharat. Penulis menggunakan Pengertian Nilai dari Bintarto, Pengertian Gotong royong dari Tashadi dkk dan Teori Solidaritas dari Emile Durkheim.

\section{Lokasi dan Waktu Penelitian}

Tempat dilaksanakannya penelitian adalah di Pakpak Bharat Kecamatan Salak, di Desa Salak.

\section{Teknik Analisa Data}

Penulis menganalisa dan
menguraikan data-data tersebut
dengan menggunakan teknik
kualitatif yaitu sebagai prosedur
pemecahan masalah yang diselidiki
denganmenggambarkankeadaaanobje
kpenelitianpadasaatsekarangKabupat
en Pakpak Bharat. Waktu penelitian
untuk mendapatkan data yang
dibutuhkan adalah tiga bulan,
terhitung mulai bulan Januari2016
sampai dengan bulan Maret 2016.

\section{Populasi dan Sampel}

\section{Populasi}

populasi dalam penelitian ini adalah seniman tari maupun orangorang yang mengerti tentang seluk beluk tarian ini di kabupatenPakpak Bharat, Kecamatan Salak Desa Salak.

\section{Sampel}

Sampel dalam penelitian ini adalah seniman dan penari masyarakat Pakpak yang memahami Tatak Tintoa Serser.

\section{Teknik Pengumpulan Data}

Teknikpengumpulan data yang dilakukanadalahsebagaiberikut:

1. Studikepustakaan

2. Observasi

3. Wawancara

4. Dokumentasi

Isi

Sebagai salah satu kecamatan di Kabupaten Pakpak Bharat, Kecamatan Salak mempunyai kedudukan, fungsi dan peranan penting baik dalam skala lokal maupun regional. Salak adalah Ibukota Kabupaten Pakpak Bharat yang terletak di daerah pegunungan. Gambaran umum Kecamatan Salak secara geografis,topografis dan demografis adalah sebagai berikut:Letak GeografisKecamatan Salak terletak antara 20 LU 960 BT, mempunyai luas wilayah sekitar $245,57 \mathrm{~km} 2$ dan terdiri dari 6 desa dan 29 dusun.

Salah satu etnis asli Sumatera Utara adalah Suku Pakpak yang bermukim pada Kabupaten Pakpak Bharat dan Kabupaten Dairi. Letak geografis 02o47'08'-02o15'49'LU 
dan 9804"12"-98o28'01"BT, Batas administrasi Kabupaten Pakpak bharat adalah sebagai berikut; sebelah Utara berbatasan dengan Kabupaten Dairi (Kecamatan Parbuluan, Kecamatan Silima Pungga-Pungga, Lae Parira, dan Sidikalang), sebelah Timur berbatasan dengan Kabupaten Toba Samosir (Kecamatan Harian), sebelah Selatan berbatasan dngan Kabupaten Tapanuli Tengah (Kecamatan Manduamas) dan Kabupaten Humbang Hasundutan (Kecamatan Tarabintang), sebelah Barat berbatasan dengan Kabupaten Aceh Singkil dan Kota Subulussalam Provinsi Aceh.

Luas Kabupaten Pakpak Bharat adalah $135.610 \mathrm{Ha}$, yang terdiri dari 8 Kecamatan (114 Desa) yakni Kecamatan Salak, Kecamatan Kerajaan, Kecamatan Sitellu Tali Urang Julu, Kecamatan Siteellu Tali Urang Jehe, Kecamatan Tinada, Kecamatan Pergetteng Getteng Sengkut,Kecamatan Siempat Rube, Kecamatan Pagindar. Pada umumnya Kabupaten Pakpak Bharat berada pada ketinggian rata-rata antara 2501.400 meter diatas permukaan laut. Dilihat dari kemiringan lerengnya, Kabupaten Pakpak Bharat memiliki keadaan lereng yang bervariasi yaitu mulai dari datar, berombak, bergelombang, curam hingga terjal. Suhu udara rata-rata berkisar antara 18 o sampai 280 C. Kelembaban udara relative rata-rata berkisar antara 86\%-92\%. Jumlah penduduk
Kabupaten Pakpak Bharat adalah sebanyak 40.884 jiwa, yang terdiri dari 20.676 jiwa penduduk laki-laki dan 20.208 jiwa penduduk perempuan. Pakpak Bharat tergolong ke daerah beriklim tropis dengan kondisi geografis berbukit-bukit. Kabupaten Pakpak Bharat beriklim sedang, dengan curah hujan pertahun sebesar $311 \mathrm{~mm}$.

\section{Mata Pencaharian Masyarakat Pakpak}

Sistem mata pencaharian kabupaten pakpak bharat masih mengandalkan sistem pertanian yang tertuju kepada macam-macam penghasilan yang diantaranya adalah, bertani padi disawah,jagung,kopi,niliam,coklat,ke menyan, cabai dan lain lain. Pada umumnya hasil pertanian yang paling lama sudah ada di kabupaten ini adalah bertani kopi dan bertani padi di sawah. Hasil padi yang telah di panen ini di perlukan untuk makanan sehari hari. Untuk sekarang ini masyarakat sudah banyak mengembangkan bertani gambir,karena gambir merupakan hasil tani yang harganya cukup tinggi. Kebiasaan masyarakat Pakpak Untuk melaksanakan kegiatan memanen atau menanam jagung, kopi, coklat, kemenyan, gambir dan padi masyarakat Pakpak melakukannya dengan beramai-ramai dan bersama-sama, ketika waktunya akan memanen atau menanam maka 
para warga desa akan berkumpul dan membagi pekerjaan mereka disawah. Ini kerap terjadi di pedesaan karena hubungan mereka yang saling membutuhkan dan melengkapi satu sama lain serta adanya tingkat saling ketergantungan yang sangat tinggi. Sehingga setiap warga akan turut membantu tetangga mereka jika melakukan kegiatan menanam atau memanen padi tanpa upah berbentuk uang, karena mereka merasa senasib dan sepenanggungan. Hal ini disebut gotong-royong.

\section{Nilai Gotong Royong dalam Tatak}

\section{Tintoa Serser}

1. Solidaritas Pada Mayarakat Pakpak

Pada umumnya masyarakat Pakpak adalah masyarakat yang hotorigen (kompak) yang di ikat oleh satu sistem kekeluargaan, budaya yang sama dan adat yang sama. Salah satu yang paling bertahan bagi masyarakat Pakpak adalah rasa solidaritas terhadap sesama dan sistem gotong royong. Unsur gotong royong tersebut terjadi karena adanya rasa kekeluargaan, rasa persamaan atau kesatuan, nasib dan norma yang berlaku yang disebut Solidaritas.

2. Nilai gotong royong pada gerak Tatak Tintoa Serser

Tatak Tintoa Serser merupakan ungkapan rasa kebersamaan, kekeluargaan dan rasa kesetiakawanan yang di ekspresikan melalui gerak. Gerak dalam Tatak Tintoa Serser merupakan gerak yang menyimbolkan aktivitas sosial sehingga mengungkapkan nilai gotong royong yang terkandung di dalamnya. Nilai gotong royong yang dimaksud dalam Tatak Tintoa Serser yaitu bagaimana tarian tersebut menyampaikan pesan yang terkandung dalam Tatak Tintoa Serser.

Pada Tatak Tintoa Serser terdapat nilai gotong royong yang dapat dijadikan pelajaran bagi masyarakat Pakpak. Pada Tatak Tintoa Serser ini juga terdapat interaksi sosial antara penari satu dengan penari yang lain karena pada dasarnya tarian ini terkandung makna nilai gotong-royong sebagai salah satu wujud kerja sama masyarakat Pakpak yang sedang memanen padi. Adapun ciri-ciri nilai gotong royong yang terkandung diantaranya adalah: 1). Adanya kerja sama antara masyarakat 2). Dapat memberi pengaruh positif terhadap setiap individu 3). Ada persamaan kewajiban dalam perbedaan gander. Ciri-ciri tersebut dapat dilihat dari gerak-gerak yang terdapat dalam Tatak Tintoa Serser dan juga terdapat dalam kehidupan sehari-hari
a. Gerak Mangirik Page/Mengirik padi


Gesture

Gerakkan mengirik padi ini dilakukan para penari untuk membersihkan padi dengan menggunakan kaki dengan cara menginjak padi dengan telapak kaki dan menyeret kaki kanan dan kaki kiri secara bergantian. Aktivitas ini dilakukan secara bersamaan dengan injakan yang tegas dan kuat, supaya padi lekang dari bulir-bulir padi atau batang padi. Gerakan ini berlaku untuk menginspirasi masyarakat Pakpak Bharat untuk selalu menjaga kebersamaan yang dulunya selalu diterapkan di kalangan desa tersebut. Ekspresi yang digunakan dalam gerakan ini adalah ekspresi riang. Pesan yang disampaikan dari gerakan ini adalah bahwa masyarakat desa dulu nya sangat erat kekeluargaannya dan kebersamaanya. Dengan adanya tarian ini mengikat warga masyarakat Pakpak untuk tetap saling menjaga kebersamaan dan hubungan silatuhrahmi yang tidak boleh putus.

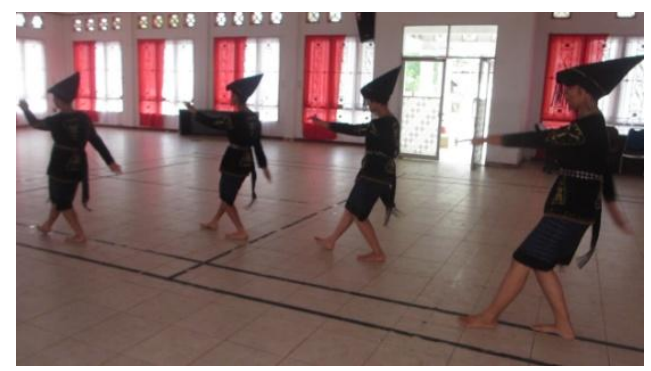

Gambar 4.3
Mangirik Page

(Dok. Pribadi 2016)

\section{b. GerakManarsari/membuang sisa padi atau padi yang kosong}

Proses membersihkan padi dimana setelah memanen padi, batang padi masih melekat pada padi-padi dan masih ada sampahsampah padinya. Gerak manarsari ini terdapat nilai bergotong royong dimana penari bergerak membersihkan padi dari sisa-sisa padi dan membuang padi yang kosong secara bersama-sama dengan semangat, agar sisa padi dan padi yang kosong terpisah dari padi yang berisi. Dalam gerakan ini mereka saling berinteraksi melalui ekspresi saling merespon antara penari satu dengan penari lainnya, penari seperti saling menyemangati untuk harus tetap gigih dalam mengerjakan pekerjaan memanen bersama. Dalam gerak ini juga menginspirasi masyarakat Pakpak untuk melestarikan sikap gotong royong yang telah ada sejak dulu. Hingga tarian ini dikemas untuk menjaga sistem kekeluargaan dalam kegiatan memanen padi. 


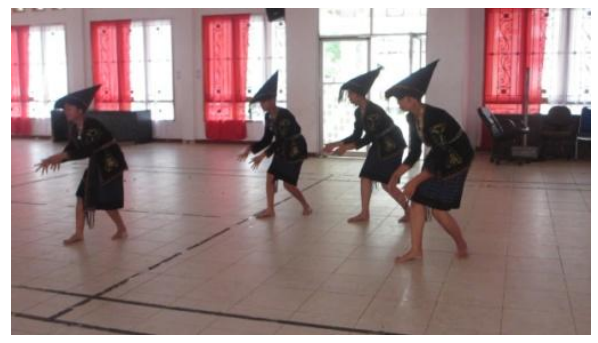

Gambar 4.4

Manarsari

(Dok. Pribadi 2016)

c. Gerak Erserakan

Page/menyerakkan padi

Gerakan Erserakan Page yang dilakukan para penari secara bersama-sama dalam Tatak Tintoa Serser memiliki semangat bergotong royong menyerakkan padi hasil panen dengan penuh rasa gembira agar padi berpisah dari sisa-sia padi. Gerakan erserakan page menggambarkan penari seperti menabur-naburkan padi dan menyerakkan padi secara bersamasama, supaya penyerakan padi terselsesaikan dengan waktu yang lebih cepat. Adanya pengaruh yang positif dalam gerak erserakan page ini adalah dimana penari bergerak dengan penuh rasa senang untuk saling memberi semangat agar erserakan page dapat terlaksanakan. Dengan adanya kerjasama tersebut setiap individu memiliki semangat dalam bekerja dikarenakan dalam kegiatan ini setiap warga saling membutuhkan dan saling bekerjasama juga mendukung satu sama lain.

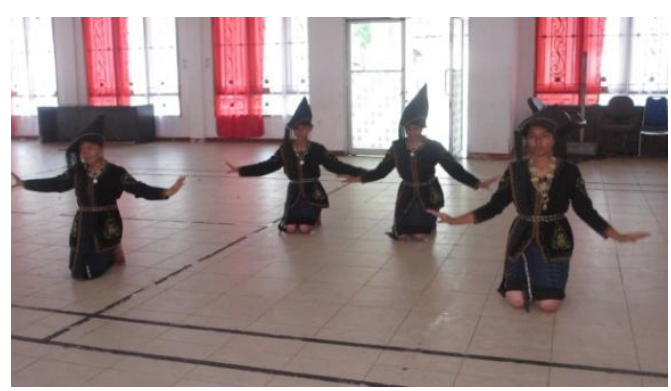

Gambar 4.5

Erseraken Page

(Dok. Pribadi 2016)

d. Gerak

MangumpulkanPage/mengumpulk an padi

Gerakkan Mangumpulkan Page menggambarkan para penari memilah-milah lagi padi yang berisi dan mengumpulkan padi-padi yang sudah bersih dari sisa-sisa padi. Mereka bergerak saling berinteraksi pada gerak ini menggambarkan bagaimana masyarakat Pakpak yang saling bekerja sama dalam bekerja dengan suasana hati yang penuh suka cita. Gerakkan ini juga dilakukan secara bersama-sama dan dilakukan dengan penuh gembira. Dalam gerakan ini pesan yang disampaikan 
adalah bahwa setiap pekerjaan jika dilakukan secara bersama-sama atau gotong royong akan menjadi lebih mudah dan hasilnya juga akan lebih baik.

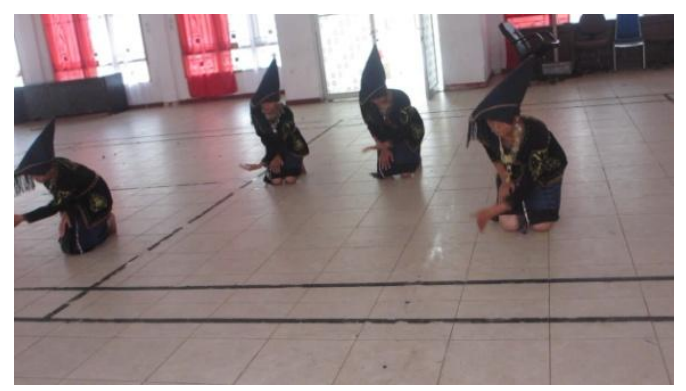

Gambar 4.6

Mangumpulkan Page

(Dok. Pribadi 2016)

e. Gerak Menjunjung

Page/menjunjung padi

Gerak Menjunjung Page ini adalah bagian terakhir dari gerak Tintoa Serser, dimana para penari menjunjung hasil panen padi nya yang sudah dibersihkan dari sisa-sisa padi, padi yang kosong dan dari batang padi yang masih melekat. Para penari bersama-sama menjunjung padi yang telah dibersihkan dan membawa padi. Aktivitas ini dilakukan secara bersama-sama dan para penari membawa hasil panen dengan gembira dikarenakan pekerjaan mereka tidak sia-sia dan membawakan hasil.

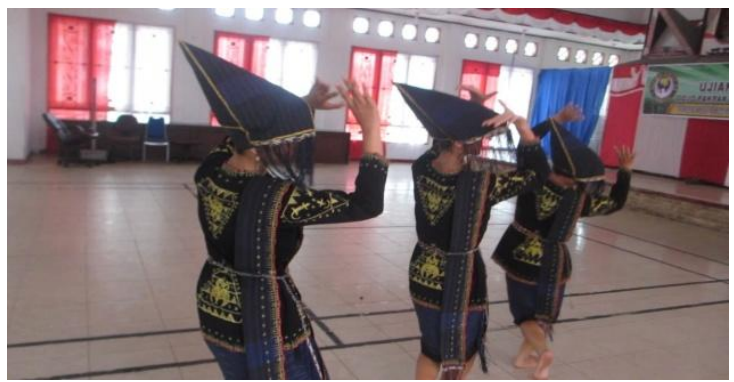

. Gambar 4.7

Menjunjung Page

(Dok. Pribadi 2016)

\section{KESIMPULAN}

Dari hasil penelitian yang dilakukan dilapangan dan penjelasan yang sudah diuraikan mulai dari latar belakang hingga pembahasan, maka disimpulkan keseluruhan terhadap Tatak Tintoa Serser di Pakpak Bharat sebagai berikut :

1. Tatak Tintoa Serserterdiri dari 9 ragam gerak yaitu : Ambe-ambe Tangan, Ser-ser Makkat-akkat, Ambe-Ambe Tangan depan Perut, Mangirik Page, Manarsari, Erserakan Page, Iangken 
Page, Mangumpukan Page

dan Menjunjug page.

2. Pesan yang disampaikan dalam setiap ragam gerak adalah bagaimana sistem gotong royong berlaku, menghimbau dan mengikat masyarakat pakpak dalam bertani sehingga melahirkan kesejahteraan dan kebahagiaan.

3. Nilai-nilai moral yang terdapat dalam

TatakTintoaserseradalah nilai solidaritas dan nilai gotongroyong. Kedua nilai ini saling berkaitan satu dengan yang lain. Rasa solidaritas dan gotong-royong dalam tarian ini ditunjukkan melalui setiap gerakannya.

\section{SARAN}

Dalam mendata dan menulis skripsi ini membutuhkan waktu dalam observasi dan penelitian yang panjang, maka dapat diajukan beberapa saran antara lain sebagai berikut :
1. Penulis berharap dengan adanya penelitian ini masyarakat Pakpak untuk menjaga, mengembangkan serta melestarikan tari-tarian yang berada pada masyarakat Pakpak khususnya di Kecamatan Salak.

2. Kepada seniman di Kecamatan Salak diharapkan tetap terus menjaga Tatak Tintoa Serser agar dapat dipublikasikan sehingga menjadi kesenian yang tidak akan punah. Dengan mengajarkan tarian ini secara baik dan benar sesuai aturanaturan yang telah ada kepada generasi penerus.

3. Dengan mengingat kepedulian terhadap kesenian daerah, berarti telah menyelamatkan anak cucu kita dari pengaruh budaya luar yang akan merusak budaya sendiri.

4. Memperkenalkan warisan budaya kepada masyarakat luas adalah salah satu wujud cara menghargai dan juga salah satu wujud kecintaan kita terhadap budaya daerah kita sendiri. 


\section{DAFTAR PUSTAKA}

Arikunto, Suharsimi, 1992.Prosedur Penelitian, Jakarta : Rineke Cipta.

Brahmana, Evariana, 2009, Analisis Nilai-Nilai Gotong-Royong, FISIP UPI, Yogyakarta.

Budiono, 2005. Kamus Besar Bahasa Indonesia, Surabaya : Kartika.

Furchan. 2004. Pengantar Penelitian dalam Pendidikan, Medan : Universitas Sumatrera Utara.

Hadi, Sumandiyo, 2005, Sosiologi Tari, Yogyakarta : Penerbit Pustaka.

Hidayat, AA. 2007. Metode Penelitian dan Teknik Analisis Data, Surabaya : Salemba Medika

Ihromi. (2000). Pokok Antropologi Budaya. Jakarta: Gramedia

Nurwani, 2014, Pengetahuan Seni

Tari, Medan : Unimed Press.

Ringgas Maibang, 2015, Mengenal Etnis Pakpak Lebih Dekat, Medan.

Rochmadi, N. 2012. "Gotong Royong sebagai Common Identoty dalam kehidupan bertetangga Negara-Negara Asean". Malang. dalam jurnal universitas Negeri Malang.

Royce, Anya Peterson. (2007). The Antthropology of Dance. (F.X Widaryanto.Terjemahan).
First Midland. Buku asli diterbitkan Tahun 1980.

Sitti Rahmah, 2015, Pengantar Pengetahuan Seni Tradisional Pakpak Dairi, Medan : Unimed Press

Sobur. 3003. "Nilai-nilai Gotong Royong dalam tari Mbuah Page (Analisis Semiotik Nilai-nilai Gotong Royong dalam tari Mbuah Page pada acara adat MerdangMerdem di desa Perbesi Kecamatan Tigabinaga Kabupaten Karo Sumatera Utara. Yogyakarta" dalam jurnal Ilmu Komunikasi FISIP UPN.

Soedarsono.(1972). Djawa Bali: Dua Pusat Perkembangan Dramaturgi Tradisionel di Indonesia. Yogyakarta: Gadjah Mada Universitas Press.

Sugiyono. (2010). Metode Penelitian Kuntitatif dan $R \& D$. Bandung : Alfabeta

Sugiyono, (2011), Metode Penelitian Kuantitatif, Kualitatif dan R\&D, Alfabeta, Bandung.

Sukamadinata. 2006. Pengendali Mutu Pendidikan Sekolah Menengah (Konsep, Prinsip dan Instrumen. Bandung : Refika Aditama.s

http://blogs.mervpolis.com/roller/adit lentry/masyarakat_perkotaan_dan_m asyarakat_pedesaan

https://www.google.co.id/webhp?sou $\underline{\text { rceid }=\text { chromeinstant\&ion }=1 \& \text { espv }=2}$ 
$\underline{\& i e=U T F-}$

$\underline{8 \# q=\text { pengertian+nilai+sosial }}$

http://www.smansax 1-

edu.com/2015/02/pengertian-

interaksi-sosial-beserta.html.

http://www.dosenpendidikan.com/pe

ngertian-manfaat-dan-prinsip-

terciptanya-solidaritas-lengkap/

https://marthabelawatitarihoran.word

press.com/2013/03/13/kis-1125-30-

solidaritas-16-maret-2013/ 